\title{
PELAYANAN PRIMA TERHADAP LOYALITAS KONSUMEN SCHATJE KIDS DI BANDUNG
}

\author{
Luthfiyah Bilqis, Ai Nunung \\ Fakultas Ekonomi dan Bisnis, Politeknik Piksi Ganesha, Program Studi Administrasi Keuangan \\ Email: luthfybilqis21@gmail.com
}

\begin{abstract}
This study aims to determine the effect of excellent service on customer loyalty. The method used in this study is the associative method with a quantitative approach. The population in this study are all customers who have purchased Schatje Kids products with a sample collection of 49 respondents. The data collection technique uses primary data sources and for data processing Validity Test, Reliability Test, Normality Test, Simple Linear Analysis Test, T Test, and Coefficient of Determination Test using SPSS version 23 software. The results in this study can be concluded that Service Prima has a positive effect on Customer Loyalty which is proven by the Test where the Sig value obtained is smaller $(0.000<0.05)$.
\end{abstract}

Keywords: Customer Loyalty, Excellent Service

\begin{abstract}
Abstrak
Pengkajian ini bermaksud untuk mengetahui pengaruh pelayanan prima terhadap loyalitas pelanggan. Metode yang dipakai pada pengkajian ini ialah metode asosiatif dengan pendekatan kuantitatif. Adapun populasi dalam penelitian ini ialah seluruh pelanggan yang telah membeli produk Schatje Kids dengan pengumpulan sample sebanyak 49 responden. Teknik pengumpulan data memakai sumber data primer dan untuk pengolahan data Uji Validitas, Uji Reabilitas, Uji Normalitas, Uji Analisis Linier Sederhana, Uji T, dan Uji Koefisien Determinasi menggunakan software SPSS versi 23. Hasil dalam penelitian ini dapat di simpulkan bahwasanya Pelayanan Prima berpengaruh positif terhadap Loyalitas Pelanggan yang di buktikan dengan pengujian T dimana nilai Sig yang di dapatkan lebih kecil $(0,000<0,05)$.
\end{abstract}

Kata kunci: Loyalitas Pelanggan, Pelayanan Prima

\section{Pendahuluan}

Pada era kesejagatan ini khususnya di Indonesia, pertumbuhan serta perkembangan dari berbagai bidang sudah semakin dinamis. Dunia usaha juga menghadapi perkembangan serta yang sangat pesat. Perihal ini bisa dibuktikan dengan terdapatnya beberapa industri baru yang menghasilkan jenis barang ataupun jasa guna memenuhi kebutuhan pelanggan.
Bagi para pengusaha baik itu di bidang produksi atau jasa tentu ingin memberikan dan mempertahankan pelayanan yang memadai ataupun meningkatkan tingkat pelayanannya menjadi lebih baik. Saat ini persaingan antar perusahaan sudah sampai ke tahap yang sangat kompetitif. Salah satu metode agar tercapainya tujuan jangka panjang ialah dengan melalui loyalitas konsumen yang telah diperoleh dari bentuk pelayanan 
prima yang diberikan perusahaan atau penjual kepada konsumen setianya.

Sesuai dengan standar pelayanan yang telah berlaku, para penjual tidak cukup apabila hanya memberikan rasa puas terhadap produk yang di dapatkan oleh konsumen. Tetapi harus memperhatikan juga bagaimana cara kita memahami apa yang di inginkan oleh konsumen sehingga dapat menimbulkan kesan yang positif dan dapat membuat konsumen senang. Contohnya, menanggapi pertanyaan para konsumen dengan ramah juga perhatian. Selain itu layanan sempurna perlu di iringi oleh bobot essentials yang mempuni, memegang visi yang melihat ke masa depan juga perlu di perjuangkan berkelangsungan guna memupuk kepabilitas para petugas layanan kendati dapat meningkatkan sumbangsih dan menyajikan pelayanan yang terbaik terhadap pelanggan. (Asih, 2016)

Mengenai penjabaran di atas, memperoleh arti bahwasanya pelayanan ialah aktifitas yang menggabungkan komunikasi antara seseorang atau lebih untuk mendapatkan kepuasan. Pelayanan konsumen dengan cepat serta tanggap membuat konsumen merasa diprioritaskan. Dengan membeli produk di Schatje Kids. Schatje Kids sebagai jasa industri manufaktur sangat mengharapkan konsumen dapat membeli kembali produk yang dijual. Oleh karena itu Schatje Kids selalu berusaha memberikan pelayanan yang baik untuk para konsumennya.

Bagi Barata (2014:31-32), aspek yang meningkatkan layanan sempurna, yakni keahlian (ability), perilaku (attitude), performa (appearance), atensi (attention), aksi (action), serta tanggung jawab (accountability). Bersumber pada uraian di atas bisa disimpulkan bahwa pelayanan memegang peranan yang sangat berarti, karena bisa menentukan apakah konsumen sudah puas ataupun belum dengan pelayanan yang terdapat di Schatje Kids, seperti dalam perihal keramahan admin, pemberian informasi dan jenis barang yang akurat, serta kecepatan dalam segi pengiriman dan juga membalas pesan konsumen.

Keluhan pelanggan dalam suatu usaha bisa di artikan sebagai sebuah penilaian yang jelas dalam memajukan servis. Bersama adanya komplain para pelanggan, pelaku pengusaha dapat memahami sesuatu yang keliru dan menjadikan pelajaran agar bisa mengupgrade sistem pelayanan yang ada agar bisa menjadi lebih baik.

Mengacu kepada pendapat Daryanto dan Setyabudi, (2014 : 32) 
diringkaskan bahwa keluhan merupakan rasa kurang puasnya konsumen terhadap penjual. maka menangani sesalan konsumen secara lebih awal ialah tindakan yang berpaham serta akurat sebab perusahaan akan lebih bisa mencegah persolahan yang dapat merugikan. Sekecil apapun kekesalan konsumen ialah keluhan yang perlu secepatnya diatasi dengan sigap dan cekatan karena mempengaruhi penilaian terhadap kualitas perusahaan. Pelayanan atau admin yang bertugas pun harus cepat tanggap dalam menangani keluhan agar mengurangi resiko pelanggan tidak puas.

Schatje Kids adalah salah satu brand anak di Kota Bandung. Berpijak sejak tahun 2015 Schatje Kids semakin mengembangkan produknya ke banyak kota bahkan sampai ke sebagian negara yang ada di Asia. Dengan semakin maraknya berjualan berbasis online atau yang biasa disebut dengan market place, maka semakin di mudahkannya juga dalam mencari kebutuhan sehari-hari ataupun untuk memenuhi gaya hidup. Kemudahan transaksi berbasis online ini membantu para konsumen berbelanja tanpa mendatangi toko tersebut, sama dengan prinsip Schatje Kids untuk memberikan pelayanan yang memuaskan dengan mengacu kepada beberapa konsep pelayanan prima; Sikap, perhatian, dan Tindakan.

Kajian ini membahas seputar pengaruh pelayanan prima terhadap loyalitas konsumen di Schatje Kids Bandung.

\section{Tinjauan Pustaka}

Pengertian Pelayanan Prima

Mengacu kepada defenisi Rangkuti (2017:49) Pelayanan prima merupakan, "suatu pelayanan paling baik yang diberikan oleh penjual dalam mencukupi harapan dan keperluan pelanggan”.

Bagi (Barata, 2014) pelayanan prima merupakan perhatian pada pelanggan dengan memberikan layanan terbaik guna meyediakan kemudahan pemuasan kebutuhan dan mewujudkan kepuasannya, agar mereka selalu setia terhadap perusahaan. Dalam memberikan servis prima kepada konsumen, Schatje Kids berpacu kepada variabel yang sudah dijelaskan oleh (Barata, 2014) yakni:

1. Kapabilitas (Ability)

Servis pelanggan mesti mempunyai kapabilitas guna membantu agar pelanggan tidak beralih kepada brand lain, misalnya dari segi komunikasi yang mempuni, kemampuan menjual dan berkesan tidak memaksa, kemampuan mengatasi masalah dengan cepat tanpa 
consumen menunggu lama, manajemen kecemasan dalam menghadapi masalah yang timbul pada saat melakukan komunikasi, sampai memahami hal yang lebih efektif seperti pemanfaatan teknologi semacam Microsoft Excel, dan perangkat lunak penunjang bisnis lainnya seperti Ecommerce Shopee, Tokopedia, Lazada, Zalora, dan masih banyak lagi.

\section{Sikap (Attitude)}

Dalam melaksanakan dan menjalankan pelayanan prima terhadap konsumen, sikap atau attitude adalah hal yang sangat utama. Karena sikap penjual menentukan kualitas dan kepuasan konsumen. Sikap yang harus diterapkan dan di junjung tinggi oleh para penjual kepada konsumen adalah ramah, sopan, penuh perhatian, berpikir sehat juga positif, memahami keinginan konsumen, serta tidak membeda-bedakan. Baik itu konsumen dengan pembelian produk terbanyak atau sebaliknya. Tidak salah juga bila sebagai penjual menjadikan konsumen sebagai raja, karena jika pelanggan puas dengan pelayanan serta konsep yang telah di berikan maka konsumen tidak akan khawatir untuk membeli ulang produk karena telah merasakan kepuasan dan kenyamanan yang telah diberikan penjual selama bertransaksi.

3. Penampilan (Appearance)

Penampilan bisa diartikan dengan tampak utama seseorang baik yang bersifat wujud maupun non wujud yang bisa menciptakan rasa asistensi diri. Begitu juga di Schatje Kids ingin menjual suatu produk, tetapi dari segi foto produk atau foto model sebagai penunjang tidak memadai. Konsumen pun akan merasa ragu untuk membeli produk tersebut karena merasa curiga dan tidak puas dengan yang mereka lihat di dalam visual. Berbeda jika Schatje Kids menjual produk secara langsung, ketika produk yang ditawarkan sudah menunjang tetapi penjual atau sales tidak berpenampilan rapi dan menarik atau bahkan jika toko tersebut terlihat kotor dari luar maka pembeli pun menjadi malas bahkan tidak mau mengunjungi toko tersebut. Sehingga dapat disimpulkan bahwa penampilan adalah hal yang paling utama dan wajib diperhatikan.

4. Perhatian (Attention)

Pada melangsungkan servis, para customer service atau admin perlu memperhatikan apa yang di inginkan oleh pelanggan. apabila pelanggan telah 
memperlihatkan kemauan guna berbelanja bahkan hanya untuk menanyakan, maka tindakan yang perlu diperlihatkan ialah memberikan atensi. Perhatian ini bisa di artikan dengan menanyakan apa yang di butuhkan oleh konsumen, selain itu perhatian dapat berupa memberikan informasi kelebihan serta kekurangan mengenai produk yang di jual. Juga Customer service atau admin dapat menuturkan salam, serta bertanya, "ada yang bisa kami bantu?". Di sini sebelumnya pelayan perlu menafsirkan terlebih dahulu mengenai produk yang di tawarkan. Jangan sampai pada saat pelanggan menanyakan produk, para pelayan kurang memahami dengan baik mengenai produk tersebut. Jika sampai demikian, maka pelanggan akan ragu untuk membeli produk yang di tawarkan sebelumnya.

5. Tindakan (Action)

Action meliputi berbagai tindakan nyata yang harus dilangsungkan dalam memberikan layanan terhadap pelanggan. Seperti pada saat menuliskan antaran pelanggan, melaksanakan pengantaran dengan apik serta terpercaya, menghasilkan servis atau barang unggul yang dipunyai, dan tidak lupa untuk berterima kasih terhadap pelanggan sebagai tanda apresiasi karena telah mempercayakan produk Schatje Kids.

6. Tanggung Jawab (Accountabillity)

Petugas pelayan wajib mempunyai kewajiban atas tugas yang ia jalani dan juga tergadap konsumen, hal ini menjadi dasar dari setiap jenis pekerjaan. Namun seringkali para pengusaha mengabaikan kewajiban layanan prima tersebut dan kian berpusat terhadap laba semata. Padahal tanggung jawab ini berakibat sangat fatal jika kita sering kali acuh, karena tanggung jawab dapat menghindarkan kerugian atau ketidakpuasan pelanggan.

\section{Pengertian Loyalitas Konsumen}

Menurut (Mowen dan Minor, 2008) mengutarakan loyalitas seperti keadaan dimana konsumen memiliki perilaku positif atas suatu label, memiliki keterikatan pada merk tersebut, dan bertujuan melanjutkan pembeliannya dimasa yang akan datang. Kesetiaan pelanggan sangat krusial untuk suatu perusahaan baik itu yang bergelut di aspek jasa maupun produk (barang) guna memupuk profit bagi suatu perusahaan, dikarenakan jika pelanggan tidak setia atas produk suatu perusahaan, maka dipastikan mereka akan berpaling ke produk kompetitor, guna menjaga kesetiaan pelanggan ada salah satu upaya untuk 
menumbuhkan kesetiaan konsumen yakni dengan memberikan pelayanan yang sempurna, yang diharapkan dapat membuat pelanggan untuk kembali melakukan transaksi.

Bagi (Griffin, 2015) mengutarakan spesifik konsumen yang setia yakni:

1. Melaksanakan pembelian refetitif secara runtut.

2. Berbelanja antar lini barang serta layanan.

3. Merekomendasikan pada orang lain.

\section{Kerangka Berpikir}

\begin{tabular}{|c|c|}
$\begin{array}{c}\text { Pelayanan } \\
\text { Prima (x) }\end{array}$ & $\longrightarrow$ \\
$\begin{array}{c}\text { Loyalitas } \\
\text { Pelanggan (y) }\end{array}$ \\
\hline
\end{tabular}

\section{Gambar 1. Kerangka Berpikir}

Gambar 1 tersebut menerangkan bahwa yang menjadi kerangka pikir untuk pengembangan penelitian ini adalah mencari pengaruh antara layanan prima terhadap loyalitas konsumen. Dengan hipotesis yang dibentuk yaitu pelayanan prima berpengaruh positif terhadap loyalitas pelanggan di Schatje Kids Bandung.

\section{Metode Penelitian}

Teknik pengkajian merupakan suatu upaya guna mendapat resolusi dari persoalan-persoalan dalam pengkajian, bagi
(Sugiyono, 2014:2) metode penelitian pada pangkalnya yaitu teknik ilmiah guna memperoleh bahan informasi bersama maksud dan kegunaan tertentu. Pengkajian yang akan digunakan dalam metode ini ialah metode survey, dengan memakai daftar pertanyaan selaku sumber bahan informasi utama yang dipunyai.

Faktor-faktor yang akan sertakan pada pengkajian ini ialah peubah (X) sebagai pelayanan prima dan variabel $(\mathrm{X})$ sebagai loyalitas konsumen. Penelitian ini diharapkan dapat membantu mengembangkan serta mengevaluasi penjualan serta branding dari produk Schatje Kids Bandung. Populasi yang dikenakan pada angket ini ialah para konsumen yang sempat membeli produk Schatje Kids serta merasakan pelayanan para pelayan dalam menjalankan tugasnya. Pertanyaan yang diberikan kepada populasi berbentuk pilihan ganda berangka yang menjabarkan kepuasan pelayanan serta loyalitas konsumen. Selanjutnya peneliti akan melangsungkan pengujian normalisasi serta penggodokan informasi statistik memakai program software SPSS 23. 


\section{Hasil penelitian dan Pembahasan}

\subsection{Hasil Penelitian}

\section{Normalitas}

Selanjutnya ialah hasil pengkajian normalitas memakai uji Kolmogrov Smirnov melalui alat bantu aplikasi SPSS 23:

\section{Tabel 1. Hasil Pengujian Normalitas Data}

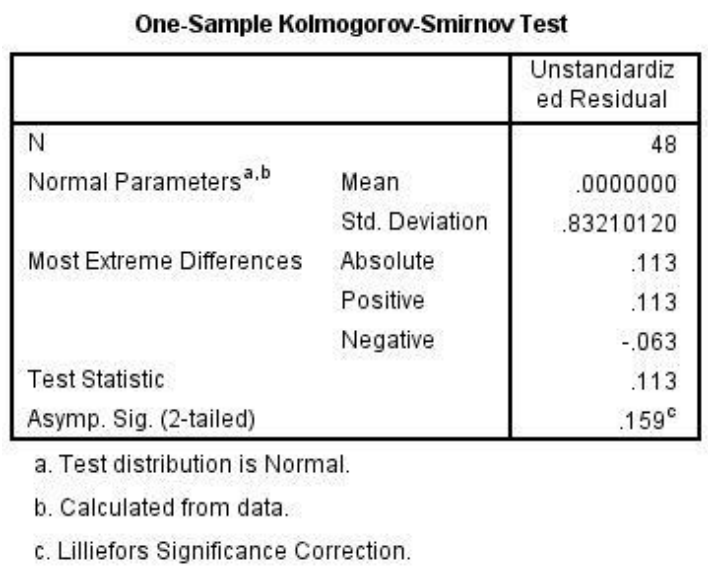

Sumber: di olah menggunakan SPSS, V.23. 2021

Berlandaskan uraian di atas, didapati perolehan angka Asymp Sig (2tailed) senilai 0,159. Dikarenakan perolehan angka Asymp Sig (2-tailed) > 0,05. Maka mengandung makna bahwasanya Pelayanan Prima dan Loyalitas Konsumen berdistribusi wajar, sehingga dapat diputuskan bahwasanya bahan informasi layak untuk dilakukan pengajuan secara statistik.

\section{Multikolinieritas}

Selanjutnya hasil pengkajian multikolinieritas melalui pengolahan alat bantu aplikasi SPSS 23 dengan nilai sebagai berikut:
Tabel 2. Analisis Regresi Linier

\section{Sederhana}

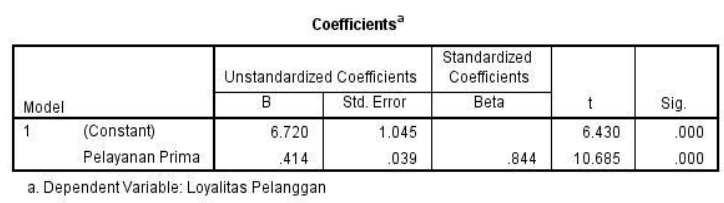

Sumber: di olah menggunakan SPSS, V.23. 2021

Berlandaskan uraian di atas bahwa angka variabel Loyalitas Pelanggan adalah 6,720 sementara nilai Pelayanan Prima (b) yakni 0,414 . Maka perserupaan regresinya ialah:

$$
Y=a+b X \text { atau } Y=6,720+0,414
$$

Koefisien b disebutkan koefisien arah regresi yang menjabarkan tranformasi pertengahan peubah $\mathrm{Y}$ guna masing masing peubah $\mathrm{X}$ senilai satuan. transformasi ini ialah peningkatan nilai $b$ berciri absolut dan pengurangan $\mathrm{b}$ berciri minus. Dengan formulasi sebagai berikut:

a. Konstanta senilai $\mathbf{6 , 7 2 0}$ menjabarkan bahwa jika tidak ada nilai Pelayanan Prima terhadap Loyalitas Pelanggan senilai 6,720

b. Koefisien regresi $X$ senilai $\mathbf{0 , 4 1 4}$ menjabarkan yatakan bahwa setiap peningkatan nilai Pelayanan Prima, maka nilai keputusan Loyalitas Pelanggan bertambah sebesar 0,414.

\section{Pengujian t-test}

Tabel 3. Uji t-test 


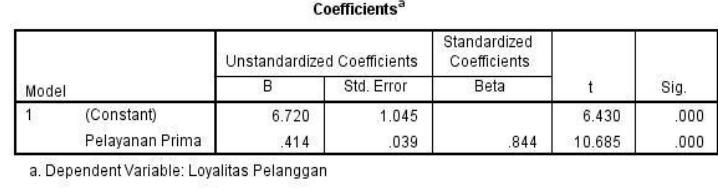

Sumber: di olah menggunakan SPSS, V.23. 2021

Berdasarkan hasil dari tabel 3 analisis uji $\mathrm{t}$ di atas antara variabel total aktiva (X) dan variable sisa dari hasil usaha (Y) diperoleh tingkat nilai signifikasi senilai $0,00<0,05$ yang mempunyai arti bahwasanya pelayanan prima berpengaruh positif terhadap loyalitas pelanggan di Schatje Kids Bandung.

Sebagai mana dugaan sementara pada pengkajian ini yang mengutarakan bahwasanya pengaruh pelayanan prima atas loyalitas pelanggan dapat dibenarkan dan terbukti.

\section{Pengujian Koefisien Determinasi} Tabel 4. Uji Koefisien Determinasi

Model Summary
\begin{tabular}{|l|c|c|c|c|}
\hline Model & R & R Square & $\begin{array}{c}\text { Adjusted R } \\
\text { Square }\end{array}$ & $\begin{array}{c}\text { Std. Error of } \\
\text { the Estimate }\end{array}$ \\
\hline 1 & $.844^{\text {a }}$ & .713 & .707 & .84110 \\
\hline
\end{tabular}
a. Predictors: (Constant), Pelayanan Prima
b. Dependent Variable: Loyalitas Pelanggan

Sumber: di olah menggunakan SPSS, V.23. 2021

Menurut hasil tabel 4 menjelaskan bahwa perolehan nilai $\mathrm{R}$ senilai 0,844 atau 84,4\%. Hasil tersebut mengandung arti pelayanan prima berpengaruh senilai $84,4 \%$ terhadap loyalitas pelanggan, sementara selisih dari $(100 \%-84,4 \%=15,6 \%)$ adalah variabel yang tidak dikaji dalam pengkajian ini.

Angka koefisien korelasi senilai 0,844. Perolehan tersebut menunjukan pengaruh dari hubungan variabel $\mathrm{X}$ (loyalitas konsumen) terhadap variabel Y (pelayanan prima) ialah kuat.

Tabel 5. Tabel tingkat Hubungan

\begin{tabular}{|l|l|}
\hline \multicolumn{1}{|c|}{ Interval Korelasi } & Tingkat Hubungan \\
\hline $0,00-0,199$ & Kuat \\
\hline $0,20-0,399$ & Rendah \\
\hline $0,40-0,599$ & Sedang \\
\hline $0,60-0,799$ & Kuat \\
\hline $0,80-0,1000$ & Sangat Kuat \\
\hline
\end{tabular}

Sumber: Sugiyono (2014:250)

\subsection{Pembahasan Penelitian}

Berdasarkan hasil pengkajian didapati bahwasanya pelayanan prima berpengaruh signifikan terhadap loyalitas pelanggan di Schatje Kids Bandung. Dengan tingkat kaitan senilai $84,4 \%$ yang mengandung makna bahwa pelayanan prima memilki peran yang sangat besar dalam meningkatkan loyalitas pelanggan di Schatje Kids. Dengan demikian semakin tinggi tingkat kesesuaian pelayanan prima maka semakin tinggi pula loyalitas pelanggan dan sebaliknya. Hasil yang didapati dalam pengkajian ini memperkuat penelitian terlebih dahulu yang dilakukan oleh Saputra, dkk (2015), dewi, dkk (2019), Bilgah 
(2019), Karami \& syahputra (2021), yang mengungkapkan bahwa Pelayanan prima berpengaruh terhadap loyalitas pelanggan. Pelayanan Prima yang didapatkan pelanggan menjadi tolok ukur dalam mendapatkan kesuksesan dan dapat mengadirkan loyalitas serta kepuasan pelanggan dalam memperoleh barang atau jasa.

Schatje Kids merupakan salah satu usaha di bidang pakaian anak yang ada di Kota Bandung. Perkembangan usaha pakaian anak ini disebabkan oleh banyaknya peningkatan kebutuhan konsumen, jika dilihat dalam persaingan bisnis pakaian anak tentu Schatje Kids bukanlah satu-satunya brand local yang menjual produk pakaian anak. Oleh karena itu Schatje kids terus berusaha mengembangkan produknya baik dari segi kualitas bahan, pengemasan, kecepatan pengiriman, dan yang lebih utama ialah meningkatkan kualitas pelayanan prima terhadap konsumen.

Tidak jarang pihak Schatje Kids seringkali menghadapi beberapa keluhan konsumen mengenai pelayanan terhadap konsumen, permasalahan tersebut seringkali terjadi akibat pelayanan yang acuh terkesan tidak ramah, serta lebih memfokuskan kepada produk yang di jual sedangkan pelayanan tersebut tidak maksimal. Masalah-masalah tersebut dapat menimbulkan rasa ketidak nyamanan yang diberikan oleh pihak Schatje Kids.

Dengan demikian yang harus di garis bawahi ialah pelayanan prima sebagai ujung tombak dari sebuah bisnis. Sebab apabila pelayanan prima tidak ditingkatkan maka akan ada banyak sekali kemungkinan konsumen lain akan beralih kepada brand lokal yang lebih baik dalam segi pelayanan.

\section{Simpulan dan Saran}

\subsection{Simpulan}

Keputusan yang ditetapkan dari pengkajian serta pembahasan materi di atas yakni bahwa dengan di terapkannya Pelayanan Prima cukup efektif untuk meningkatkan tingkat loyalitas konsumen terhadap pembelian ulang produk juga meningkatnya kepercayaan terhadap segi kualitas serta pelayanan yang di terapkan oleh Schatje Kids. Variabel yang di libatkan penelitian ini ialah variabel (X) sebagai pelayanan prima dan variabel (Y) sebagai loyalitas konsumen. Dengan output yang diperoleh bahwa antara pelayanan prima dengan loyalitas konsumen memiliki pengaruh yang tinggi dan sudah dibuktikan berdasarkan hasil kajian di atas.

\subsection{Saran}

a. Adapun dampak positif dari diterapkannya pelayanan prima terhadap konsumen Schatje Kids ialah 
meningkatnya kepercayaan terhadap produk juga keterbukaan dari pihak Schatje Kids terhadap para konsumen yang memicu adanya rasa loyalitas terhadap brand tersebut, oleh sebab itu sebaiknya pelayanan Schatje Kids lebih ditingkatkan lagi agar tetap mampu bersaing dengan kompetitornya.

b. Pelayanan Prima mampu meningkatnya jumlah konsumen yang sering membeli ulang atau repurchase produk Schatje Kids karena pelayanannya yang ramah. Meskipun brand lain menjual produk yang sama dengan Schatje Kids atau bahkan lebih baik dalam segi bahan serta harga, pelanggan tetap akan tetap memilih untuk membeli produk Schatje Kids dikarenakan sudah sangat puas dengan pelayanan yang diberikan.untuk itu pelayanan yang ada dapat dikembangkan lagi dan memberikan daya tarik yang berbeda bagi pelanggan dapat dilakukan dengan memberikan hadiah khusus untuk pelanggan yang sudah menjadi langgan selama sekian bulan atau tahun dengan membuatkan iklan promonya.

\section{DAFTAR PUSTAKA}

Asih, N.S., Nuridja, I.M. and Zukhri, A., (2016). Pengaruh Pelayanan Prima (Service Excellent) terhadap Kepuasan Pelanggan Salon Agata
Singaraja. Jurnal Pendidikan Ekonomi Undiksha, 7(2).

Batlajery, Semuel. Alfons, Marlyn E. Analisis Pelayanan Prima Terhadap Loyalitas Pelanggan Pada Hotel Megaria. MUSAMUS: Journal of Businness \& Management. Volume II, No. 1, Oktober 2019. Doi: 10.35724/MJBM. v2i1.2318

Barata, Adya. (2014). Dasar - Dasar Pelayanan Prima. PT. ElexMedia Komputindo, Jakarta.

Bilgah. (2019). Pengaruh Pelayanan Prima Terhadap Loyalitas Pelanggan Pada PT Fast Food Indonesia Tbk KFC Cabang Ramayana cibubur Jakarta Timur. Cakrawala, 19(2), 231-236. Retrieved from doi: https://doi.org/10.31294/jc.v19i2.

Daryanto, \& Setyobudi, I. (2014). Konsumen dan pelayanan prima. Yogyakarta: Gava Media

Dewi, Anak Agung Sasmita. Susanto, Budi. Dan Budiarta, I Putu.(2019). Strategi Pelayanan Prima Bagi Pelanggan Villa Air Bali Boutique Resort And Spa. Media Bina Ilmiah Vol.13 No.10 Mei 2019. Hal:1649-1655

Griffin , Jill. (2015). Customer Loyality. Kencana, Jakarta.

Karami, Iqhsan Abi. Syahputra. 2021. Pengaruh Kualitas Pelayanan Terhadap Loyalitas Pelanggan PT.Tiki Jalur Nugraha Eka kurir jne Cabang Bandung. E Proceeding Of Management: Vol:8 No. 1 Februari $2021 \mathrm{Hal}: 348-354$ 
Mowen, John. dan Michael Minor. 2008. Perilaku Konsumen, jilid 2, Edisi kelima. Jakarta:Erlangga.

Saputra, F.A., Nugraha, H.S. And Widiartanto, W., 2015. Pengaruh Pelayanan Prima Dan Harga Terhadap Loyalitas Pelanggan (Studi Pada Pelanggan Layanan Pt. Pos Indonesia Semarang). Jurnal Ilmu Administrasi Bisnis, 4(3), Pp.216223.

Sugiyono. 2014. Metode Penelitian Pendidikan Pendekatan Kuantitatif, Kualitatif, dan R\&D. Alfabeta, Bandung.

Rangkuti, Freddy. 2017. Meningkatkan Kinerja Melalui Pelayanan Prima Plus Analisis Kasus Jasa Raharja. Jakarta: PT Gramedia Pustaka Utama. 